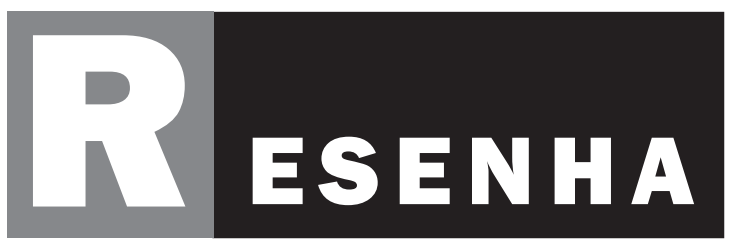




\section{RIVERA CUSICANQUI, Silvia. Un mundo Ch'ixi Es Posible: Ensayos Desde un Pre- sente en Crisis. Buenos Aires: Tinta Limón, 2018.}

\section{Spensy Kmitta Pimentel}

Universidade Federal do Sul da Bahia, Porto Seguro, Bahia, Brasil

\section{RESUMO}

A resenha analisa o mais recente livro da socióloga boliviana Silvia Rivera Cusicanqui. Os quatro ensaios contidos na obra retomam o uso do termo aymara ch'ixi (abigarrado), além de vários outros conceitos nessa língua andina, para pensar a realidade boliviana dos tempos atuais (qhipnayra). O livro traz ainda uma série de reflexões sobre a relação "bovarista" dos intelectuais mestiços latino-americanos com o contexto colonial que vivem em seus países (exortando-os a reconhecerem sua potência pa chuyma - duplas entranhas -, em lugar de permanecer nessa alienação) e retoma as obras de diversos autores bolivianos do século XX para demonstrar que os chamados "estudos decoloniais" não constituem uma novidade, e sim uma usurpação. Também tece críticas ao governo Evo Morales (2006-2019) como exemplo típico dos impasses vividos pelo novo progressismo latino-americano nas duas últimas décadas - considerados não só como parte de uma crise de valores, mas de uma crise epistêmica muito mais ampla.

Palavras-chave: Bolívia, Descolonização, Epistemologias indígenas, Ch 'ixi, Abigarrado.

\section{ABSTRACT}

The review analyzes the most recent book by the bolivian sociologist Silvia Rivera Cusicanqui. The four essays contained in the work resume the use of the term aymara ch'ixi (abigarrado), in addition to several other concepts in that andean language, to reflect the bolivian reality of the present times (qhipnayra). The book also brings a series of reflections on the "bovarista" relationship of latin american 
mestizo intellectuals with the colonial context living in their countries (urging them to recognize their pa chuyma potency - double entrails), instead of remaining in this alienation and resumes the works of several 20th century bolivian authors to demonstrate that the so-called "decolonial studies" are not a novelty, but a usurpation. It also criticizes the Evo Morales government (2006-2019) as a typical example of the impasses experienced by the new latin american progressivism in the last two decades - considered not only as part of a crisis of values, but of a much wider epistemic crisis.

Keywords: Bolivia, Decolonization, Indigenous epistemologies, Ch'ixi, Abigarrado.

Em seu mais recente livro, a socióloga boliviana Silvia Rivera Cusicanqui dá continuidade a suas reflexões que partem de conceitos ${ }^{1}$ indígenas andinos, em língua aymara, para pensar a realidade qhipnayra de seu país. O conceito redefine o termo que normalmente utilizaríamos para definir o "contemporâneo", já que esse tempo "presente" aí definido é, segundo ela, mais próximo das noções de Benjamin (1987) sobre a história - o passado é tudo o que podemos ver, e o futuro é apenas um fardo que carregamos em nossas costas, sem poder enxergá-lo, explica ela.

A ideia de "mundo ch'ixi”, por sua vez, como volta a abordar a autora, é uma referência às reflexões que em língua aymara se faz sobre o abigarrado, um termo que define superfícies em que partes de distintas cores - negras e brancas, por exemplo - são reconhecíveis, de perto, mas que, à distância, parecem de um cinza homogêneo. Pode-se "visualizar" o conceito pensando no granito, por exemplo, ou na pele de animais malhados. Países colonizados como a Bolívia seriam ch'ixi, por exemplo, no sentido de, contemporaneamente, reunirem, em seus territórios, realidades muito distintas, convivendo lado a lado - algumas relacionadas ao capitalismo de matriz europeia, outras às origens culturais pré-hispânicas.

Tais conceitos são tomados não somente como base para análises da realidade indígena, estritamente, mas de uma compreensão mais ampla sobre os processos pelos quais o país tem passado nas últimas décadas, tecendo críticas contundentes a aspectos do chamado "ciclo progressista" por que passou a América Latina.

Vale dizer que, como anuncia nota da editora logo ao início do livro, os escritos apresentados na coletânea desenvolvem-se de forma fragmentária, atentando propositalmente contra

1 Para fins de exposição, os conceitos retirados de Rivera Cusicanqui (2018) serão indicados entre aspas e com a páginação, a tradução dos conceitos foi realizada pelo autor. 
o "fetichismo dos conceitos" e refletindo um pensamento que tem se desenvolvido a partir de falas públicas, as quais, mais do que constituírem-se como blocos fechados e pré-formulados de raciocínios, abrem-se a diálogos. Trata-se, pois, de um exercício epistemológico, que busca afinação com um trabalho símbolo da carreira da autora, os Talleres de História Oral Andina (THOA), criados nos anos 80 e resultantes em uma produção com forte reconhecimento no contexto dos estudos latino-americanos.

Por sinal, além das várias críticas à administração de Evo Morales (2006-2019) e outros representantes dos chamados “governos progressistas”, Rivera Cusicanqui (2018) também provoca os acadêmicos adeptos dos chamados estudos decoloniais. Os pensadores que refletiram sobre os processos de descolonização na África, tais como Franz Fanon, lembra Rivera Cusicanqui (2018), serviram de inspiração, entre os anos 70 e 80, para intelectuais ch'ixi como Fausto Reinaga, os quais verdadeiramente identificaram-se com esses escritos a partir de sua experiência pessoal de "insulto racial, negação e esbulho" (p. 26). Já essa geração que surge a partir dos anos 90 - "Mignolo e companhia", segundo ela - fez um trabalho que basicamente se resumiu a criar "satrapias acadêmicas nas universidades mais elitistas do Norte, vendendo a suas novas audiências a ideia da descolonização, rebatizada como o 'pós-colonial' ou o 'de(s) colonial"" (p. 27).

Segundo a autora, o pensamento derivado de uma identificação visceral com as chagas abertas do colonialismo, tal como descrevem os autores africanos da luta pela descolonização, desenvolvido por esses "autores ch'ixi” que convivem e estão lado a lado com os indígenas, não pode ser comparado a algo desenvolvido em universidades elitistas de países ricos também porque, se há uma crítica central que aparece, é a condição colonizada das elites políticas e intelectuais latino-americanas.

Entre as "formas e gestos dessa mestiçagem colonial andina" está o "bovarismo" (p. 27 28) dessas elites, identificado pelo escritor boliviano Franz Tamayo - em alusão à obra Madame Bovary, de Gustave Flaubert.

Essa noção me servirá de metáfora para compreender o bloqueio que nos impede de ser memorios os com nossa própria herança intelectual. Pois resulta paradoxal e lamentável que tenhamos que legitimar nossas ideias recorrendo a autores que pusera na moda os assuntos do colonialismo, desconhecendo ou menosprezando trabalhos te ricos anteriores, que, ainda que não tenham usado as mesmas palavras - e aliás, sim, as usaram - puderam interpretar e interpelar a experiência colonial, e particularmente a colonização intelectual das elites (hoje rebatizada como "colonialidade do saber entratrevimento e veracidade (TAMAYO, 1979, p. 28). 
O intelectual mestiço, conforme a autora, deve buscar a potência de sua natureza $p a$ chuyma - duplas entranhas - e reconhecer a trama índia de seu próprio pensamento, buscando dialogar com as comunidades em seus próprios idiomas e extraindo dessa duplicidade uma “potência epistemológica". Mas, para isso, é preciso "fechar os livros e abrir os olhos para a vida" (TAMAYO, 1979, p. 34).

Ainda no primeiro ensaio, “Um mundo ch'ixi é possível: memória, mercado e colonialismo", resultado de um diálogo travado na Universidade Nacional Autônoma do México, em 2011, Rivera Cusicanqui (2018) dá um exemplo concreto do que propõe: parte de uma questão surgida no evento para fazer o exercício de esboçar uma possível "teoria ch’ixi do valor" - ou seja, uma teoria do valor que dialoga não somente com as clássicas reflexões marxistas sobre a sociedade capitalista de matriz europeia, mas que também busca elementos na vivência da autora, além da historiografia e da bibliografia sociológica, para mostrar que, num ambiente como o boliviano, composto por uma "heterogeneidade multitemporal", há muito mais em jogo para entender as atitudes dos povos andinos perante a colonização do que apenas as regras da economia política ocidental. "Para isso é necessário retomar o paradigma epistemológico indígena, uma epistemologia em que os seres animados ou inanimados são sujeitos, tão sujeitos como os humanos, ainda que sujeitos de uma natureza muito outra" (p. 90).

A referida reflexão sobre o caráter qhipnayra do presente conecta-se com uma noção central para a análise do ciclo de governos progressistas latino-americanos, a de desenvolvimento. Significativamente, o termo "buen vivir", ou sumak kawsay, não é utilizado pela autora, que, em outras ocasiões (RIVERA, 2011), já criticou o fato de ele ter sido apropriado pelos Estados da Bolívia e do Equador, para fins de autopromoção, sem o devido diálogo com os povos originários desses países sobre seus reais sentidos. As palavras são "expropriadas" dos povos em luta, sendo utilizadas para manter um sistema de "clientelismo coletivo e regalias ampliadas" (p. 110).

A onda progressista, diz a autora, manteve antigas formas de inserção das elites locais latino-americanas no mundo globalizado, fetichizando os "processos de câmbio" a partir de uma concepção de tempo que projeta as expectativas da população para um futuro que, segundo uma visão tradicional dos povos indígenas, na leitura da autora, está longe de ser o guia para um projeto político efetivo - pelo contrário, sendo o presente qhipnayra, o futuro é um fardo, pois, como não podemos vê-lo, só nos traz ansiedade. Se bem compreendi o texto, nesse sentido, para alcançar um projeto efetivamente popular, seria necessário ampliar o diálogo com a tradição, o passado, em vez de somente falar em futuro, progresso, desenvolvimento etc.

O segundo ensaio avança nessa crítica às “palavras mágicas” associadas à onda progres- 
sista. A crise civilizatória atual, afinal, é uma crise de valores que é também uma crise epistêmica, segundo a autora. A nova Constituição boliviana de 2009 foi, nessa visão, uma "cortina de fumaça" (p. 93) para disfarçar as manobras das elites que lhe permitiram manter seu status e projetos, de forma disfarçada pelas "palavras mágicas" fornecidas pelo governo do indígena Evo Morales - numa espécie de "mais valia simbólica" (p. 100).

O texto foi escrito em 2016, portanto, aos dez anos de governo Evo. A autora lamenta as "oportunidades perdidas" (p. 104-107) no período, como a de se mudar estruturalmente a cadeia produtiva da coca, desviando-a da associação ao narcotráfico. Rivera Cusicanqui (2018), por sinal, chega a denunciar iniciativas públicas que, na prática, significaram um suporte ao crime organizado ligado ao tráfico internacional de cocaína, segundo ela.

A forma do MAS de governar, de acordo com a autora, constituiu uma "sociedade de cúmplices" em torno do capitalismo extrativista, utilizando- se de "militantes fusível" (p. 112), facilmente descartáveis - somente permanecem junto ao governo os que são "cooptáveis, corruptíveis e tolerantes com a corrupção". "Capitalismo selvagem com partido único, a isso se parece reduzir-se a fórmula de bom governo de Evo, tanto como a de Lenin e a de Maduro" (p. 105-6), diz ela, em alusão aos então presidentes de Equador e Venezuela. Tudo isso em prol de uma ideia desenvolvimentista que cativou uma diversidade de sujeitos coletivos, fazendo-os indiferentes "à liquidação de formas comunitárias viáveis, inclusive aquelas que nos permitiriam enfrentar com recursos próprios a crise climática e a escassez de água” (p. 106).

Outro ponto recorrente de crítica diz respeito ao posicionamento da autora em relação ao feminismo. O governo Evo, ela acusa - o progressismo latino-americano, de modo geral -, foi composto por "esquerdomachos", "misóginos" (p. 110-111). Por outro lado, no primeiro ensaio, ela rejeita a ideia de que à tendência à construção de fraternidades masculinas deva se contrapor a criação de "antifratrias femininas". Ela sugere pensar a situação a partir da ideia de taypi, uma zona de contato em que se entreteçam os princípios masculino e feminino (p. 56). O princípio ch 'ixi, então, soa como a reflexão sugerida por Lévi-Strauss a partir das mitologias ameríndias e retomada recentemente por autores como Perrone-Moisés (2011, p. 867), um “dualismo em perpétuo desequilíbrio".

O terceiro ensaio, "Oralidade, olhar e memórias do corpo nos Andes", aprofunda e adensa a reflexão que aparece espalhada pelo livro a respeito da relação entre a pesquisadora, o seu país e o seu povo como fundamento do trabalho realizado - as "vivências e emoções que acompanham o ato de pensar" (p. 121). A autora explica que, em aymara, há duas formas de pensar - lup 'iña e amuyt'aña. Lup 'iña é “pensar com a cabeça clara”. Mas amuyt'aña é pensar com as entranhas superiores - pulmões, coração, fígado (conjunto conhecido como chuyma). 
Refletindo sobre sua própria criação - a "mãe substituta" (wawa) aymara, bem como seu sobrenome materno; o trabalho, quando jovem, como professora numa comunidade qhichwa; os THOA - a autora disserta sobre a relação entre oralidade, memória e identidade nos Andes, relatando sua busca pela "memória esquecida, reprimida, oprimida", até a noite em que sonhou pela primeira vez em aymara - "senti que o recordava depois de quatro gerações" (p. 134).

No quarto ensaio, "Micropolítica andina: formas elementares de insurgência cotidiana", a autora traça paralelos entre discussões realizadas por Rolnik e Guattari (1986) em torno da ideia de "micropolítica" e a política praticada pelos aymara kataristas, nos anos 80, bem como as mobilizações populares - "micropolíticas de rebeldia" - que antecederam a eleição de Evo Morales em 2006. Completa o volume uma entrevista, realizada pelo argentino Francisco Pazzarelli, em que a autora desenvolve diálogo sobre mais alguns aspectos ligados à ideia de $c h$ 'ixi.

Mesmo anterior ao golpe que derrubou Evo Morales em 2019, o livro consegue apresentar-se como um compêndio de alta densidade teórica sobre o cenário que levou à derrocada do ciclo progressista latino-americano, com sua incapacidade de ultrapassar os limites sociais, políticos, econômicos e, por que não, epistemológicos impostos pelo capitalismo neoextrativista no continente.

\section{REFERÊNCIAS}

1. BENJAMIN, Walter. Sobre o conceito de história. In: BENJAMIN, Walter. Magia e arte, técnica e política: obras escolhidas. São Paulo: Brasiliense, 1987. 1 v.

2. GUATTARI, Felix; ROLNIK, Suely. Micropolítica: cartografias do desejo. Petrópolis: Vozes, 1986.

3. PERRONE-MOISÉS, Beatriz. Bons chefes, maus chefes, chefões: elementos de filosofia política ameríndia. Revista de Antropologia, v. 54, n. 2, p. 857-883, 2011. Disponível em: https://www.revistas.usp.br/ra/article/download/39649/43145. Acesso em: 25 set. 2020.

4. RIVERA CUSICANQUI, Silvia. Entre el buen vivir y el desarrollo: una perspectiva indianista. In: ERREJÓN, Iñigo; SERRANO, Alfredo. (Ed.) ¡Ahora es cuándo, carajo! Del asalto a la transformación del Estado en Bolivia. España: El Viejo Topo, 2011.

5. RIVERA CUSICANQUI, Silvia. Un mundo ch'ixi es posible: ensayos desde un presente en crisis. Buenos Aires: Tinta Limón, 2018.

6. TAMAYO, Franz. Obra Escogida. Caracas: Fundación Biblioteca Ayacucho, 1979. 


\section{Spensy Kmitta Pimentel}

Doutor e Mestre em Antropologia pela Universidade de São Paulo. Professor na Universidade Federal do Sul da Bahia. Líder do Grupo de Pesquisa Comunidades e(m) Autonomia no Sul da Bahia. ID ORCID: https://orcid.org/0000-0001-7256-9384. E-mail: spensy@ufsb.edu.br. 